Article

\title{
Impacts of Autonomous Vehicles on Consumers Time-Use Patterns
}

\author{
Saptarshi Das ${ }^{1}$, Ashok Sekar ${ }^{2}$, Roger Chen ${ }^{1}$, Hyung Chul Kim ${ }^{3}$, Timothy J. Wallington ${ }^{3}$ \\ and Eric Williams ${ }^{1, *}$ \\ 1 Golisano Institute for Sustainability, Rochester Institute of Technology, 190 Lomb Memorial Drive, \\ Rochester, NY 14623, USA; saptarshi.das@outlook.com (S.D.); rbcgis@rit.edu (R.C.) \\ 2 LBJ School of Public Affairs, University of Texas at Austin, 2300 Red River Street, E-2700, Austin, TX 78712, \\ USA; s.ashok.7@gmail.com \\ 3 Research and Advanced Engineering, Ford Motor Company, 2101 Village Road, Dearborn, MI 48121, USA; \\ hkim41@ford.com (H.C.K.); twalling@ford.com (T.J.W.) \\ * Correspondence: exwgis@rit.edu
}

Received: 3 November 2017; Accepted: 5 December 2017; Published: 13 December 2017

\begin{abstract}
We use the American Time Use Survey (ATUS) to characterize how different consumers in the US might use Autonomous Vehicles (AVs). Our approach is to identify sub-groups of the population likely to benefit from AVs and compare their activity patterns with an otherwise similar group. The first subgroup is working individuals who drive to work with long total travel times. Auto-travelers in the top $20 \%$ of travel time number 19 million and travel $1.6 \mathrm{~h}$ more on a workday than those in the bottom $80 \%$. For car-commuting professionals, the additional travel time of the long-traveling group comes from $30 \mathrm{~min}$ less work, $29 \mathrm{~min}$ less sleep, and $30 \mathrm{~min}$ less television watching per day. The second subgroup is working individuals with a long travel time and who take public transport. Long public transit riders show very similar differences in activity times as the driving subgroup. Work, sleep, and video functionalities of AVs are presumably in high demand by both groups. The third sub-group identified is elderly retired people. AVs enable mobility-restricted groups to travel more like those without restrictions. We compare two age groups, $60-75$ years and $>75$ years old, the latter, on average, experiencing more mobility restrictions than their younger counterparts. The retired population older than 75 years numbers 16 million and travels 14 min less per day than retirees aged 60-75 years. The main activity change corresponding to this reduced travel is $7 \mathrm{~min}$ per day less shopping and $8 \mathrm{~min}$ per day less socializing. If older retired people use AVs to match the lifestyle of the 60-75 years old group, this would induce additional personal travel and retail sector demand. The economic, environmental and social implications of AV are very difficult to predict but expected to be transformative. The contribution of this work is that it utilizes time-use surveys to suggest how AV adoption could induce lifestyle changes inside and outside the vehicle.
\end{abstract}

Keywords: autonomous vehicles; time-use; demand; activity shifts

\section{Introduction and Background}

Autonomous vehicles (AVs) have been described as a disruptive technology [1]. Similar to the introduction of internal combustion engine vehicles at the beginning of the 20th century, AVs can significantly alter our living and working environments [2]. The highest potential for disruption is associated with the highest level of automation, dubbed level five, in which the vehicle can drive itself with or without human interaction. One potential disruption is that by expanding the range of activities that can be done in a vehicle, AVs may increase the utility of in-vehicle time, potentially reorganizing decisions on what trips to take and where to live. In addition, level five autonomous 
vehicles can enable mobility in population segments currently unable to drive (elderly and youth). There is also potential for AVs to improve vehicle sharing between households.

While there is much uncertainty in the future development, adoption and use of AVs, their potential transformative effects have become an active area of research. The potential benefits of automated vehicles, such as increased mobility of the elderly, greater safety, smoother flow of traffic, and possible costs such as increased emissions and threats from hackers have been assessed [1,2]. Fagnant and Kockelman (2015) estimated economic implications of the deployment of autonomous vehicles in the US [3]. Other studies have looked at specific application of autonomous vehicles and the resulting benefits. These include, potential reduction of greenhouse gas (GHG) emissions from light duty vehicles [4,5], potential reduction in number of on road vehicle in Texas, through optimal vehicle allocation [3], and finding optimal speed of travel and route selection that ensures traveler comfort and their ability to engage in fruitful activities [6-10].

Harper, et al., (2016) estimate upper bounds for increased travel induced by AVs due to increased mobility from non-driving senior populations and people with travel-restrictive medical conditions [11]. Their study explored three demand wedges. In demand wedge one, non-drivers are assumed to travel as much as the drivers within each age group and gender. Demand wedge two assumes that the driving elderly (those over age 65) without medical conditions will travel as much as a younger population. Demand wedge three makes the assumption that working-age adult drivers (ages 19-64) with medical conditions will travel as much as working age adults without medical conditions within each gender, while the driving elderly with medical any travel-restrictive conditions will travel as much as a younger demographic within each gender in a fully automated vehicle environment.

The market adoption of non-AV technologies such as alternative fuel vehicles has been studied extensively in the travel demand literature [12-14]. While not applied to AVs, demand for activities and time have also been addressed [15-17].

The question addressed in this work is how will different consumer groups change their activity time allocation if they are to acquire AVs? The current stage of development for AVs has not matured to the point where actual revealed adoption is observable, making it difficult to characterize its market demand. To briefly recount prior research on the adoption and use of AVs, a stated preferences survey of future $\mathrm{AV}$ use in Netherlands for example reveal that AVs may be used for last mile transit to and from train stations [18]. The same has also been suggested by the US Department of Transportation [19]. Another study in California suggests that individuals are most attracted to potential safety benefits, the convenience of not having to find parking, and amenities such as multitasking while end-route [20]. Others have pointed out that $\mathrm{AVs}$ have the potential to save on travel time, energy use and carbon impacts [21-24].

We consider use of level five, fully self-driving AVs by comparing time-use patterns of different drivers/consumers in the US. Although there are studies that acknowledge the potential for AVs to change the behavior of individuals [25], there is a lack of literature on trying to quantify the same. By using time-use data, we analyze how individuals might re-distribute their time spent on various activities. There are some studies that have looked at the impact of travel pattern on activity scheduling [26,27]. Chen and Armington (2016) considered the scheduling of in-vehicle activities in household travel and activity patterns using autonomous vehicles [28]. Our analysis is rooted in the idea that as time is constrained to $24 \mathrm{~h}$ in a day, there are tradeoffs in activity choice, i.e., spending more time on a given activity is at the expense of time spent on other activities. In the academic literature Hägerstrand formalized this idea as part of his framework for time geography [29].

We consider two types of AV benefits. The first benefit of AVs is increased utility of in-vehicle time by enabling new activities to be done within the vehicle, e.g., watching television or working. Americans spend about 50 billion hours annually behind the wheel compared to 240 billion hours annually at work. Most of these driving hours are neither productive nor provide positive utility [30]. This benefit of AVs is higher for those spending more time traveling. This additional travel time comes 
at the expense of other activities, the demand for which may be characterized by the activity patterns of workers who travel less.

The second AV benefit is enabling travel by those physically or legally constrained from driving, i.e., the elderly, the young, and the disabled. The constraint of being at home shifts activity patterns from what they may have otherwise been given access to mobility. Comparing activity patterns of a group with limited mobility to an otherwise similar cohort allows characterization of what activities were being sacrificed and how the pattern might change given access.

Having selected a group of potential adopters, we compare their activity pattern with an otherwise similar group. Activity pattern here refers to the profile of average daily time spent on activities such as sleeping, working, eating, using a computer, socializing or watching television. Differences in activity patterns between the two groups is indicative of how the adopting group might shift their patterns with access to an AV. e.g., we take the demographic that is working professionals under the age of sixty and divide them based on their travel time into the upper $20 \%$ and lower $80 \%$. The assumption is that working professionals have similar time-use demand during the weekday. Therefore, if the upper $20 \%$ sleep less than their comparative group, the lower $80 \%$, we suggest that the adopter may want to use an AV to partially to get more sleep. A study of this nature helps identify individual's potential latent demand for activities and posit how autonomous vehicles may be able to address them.

By no stretch of the imagination does our comparison of activity patterns "solve" the challenge of forecasting AV demand and use. No method can reliably forecast how consumers will react to a new technology. Being a transformative technology, AV use is particularly difficult to predict. AV adoption is, however, of such importance that an array of forecasting perspectives should be employed. In this work, we aim to add prospective analysis of time use patterns to the methodological toolkit for AV forecasting. We leverage the federal investment in the American Time Use [31] Survey to provide a new perspective on potential markets that AVs can penetrate, their size, as well as some of the features that such vehicles should possess to ensure more fruitful utilization of the in-vehicle time.

\section{Data Sources}

The analysis is based on 13 years of "The American Time Use Survey" (ATUS, 2003-2015). The American Time Use Survey (ATUS) from the Bureau of Labor Statistics provides annual time diaries for around 11,000 Americans. As with other time-use surveys, ATUS polls time diaries, a temporal sequence for a day of start and stop times for activities. Activities are matched with a predetermined list of 466 different activities in 18 categories for ATUS. In addition to activity number, respondents are polled on where and with whom the activity was done. Focusing on travel, ATUS has data on total travel time, purpose of travel, time per instance of travel, and mode of travel. Although there are other data bases like the National Household Transport Survey (NHTS) that provide time use data, ATUS provides both location and activity information, while NHTS provides only location and trip purpose information.

The ATUS has been conducted annually by the Bureau of Labor Statistics (BLS) since 2003. Annual participation exceeds 11,000 respondents, and the number of individuals surveyed between 2003 and 2015 was 170,842. Only one household member is sampled per household. The survey is conducted using computer-assisted telephone interviewing (CATI) in which the respondents indicate how they spent their time on the previous day, where they were, and whom they were with. In addition to the time-use information, ATUS also collects respondent's household level socio-economic data such as age, income, sex, race, marital status, employment status, and level of education. Table 1 shows summary sample time diary data used in this exercise.

TUCASEID is the identification number of the individual interviewed. From this table, it is evident that the individual performed 10 activities that day. TEWHERE indicates the location where the activity is performed. -1 means that the location is not disclosed. Here, 1 means the individual's residence, 4 means hotels/restaurants, 9 means a taxi/limousine. TUSTARTTIM and TUSTOPTIME indicated the beginning and end of the activity. Finally, TRCODE indicates the activity. Also, 010101 
means sleeping, 030101 means caring for children at home, 020101 means home cleaning and so on. A list of all activities is available at the ATUS website.

Table 1. Sample time diary data from the American Time Use Survey (ATUS).

\begin{tabular}{cccccc}
\hline Description & Respondent ID & Where Performed & Start Time & Stop Time & Activity Code \\
\hline ATUS Variable Descriptor & TUCASEID & TEWHERE & TUSTARTTIM & TUSTOPTIME & TRCODE \\
\hline & 20140101140007 & -1 & $4: 00: 00$ & $13: 00: 00$ & 10101 \\
& 20140101140007 & 1 & $13: 00: 00$ & $13: 30: 00$ & 30101 \\
& 20140101140007 & -1 & $13: 30: 00$ & $14: 30: 00$ & 10201 \\
& 20140101140007 & 13 & $14: 30: 00$ & $14: 40: 00$ & 181101 \\
& 20140101140007 & 4 & $14: 40: 00$ & $15: 10: 00$ & 110101 \\
& 20140101140007 & 13 & $15: 10: 00$ & $15: 30: 00$ & 181301 \\
& 20140101140007 & 9 & $15: 30: 00$ & $17: 00: 00$ & 130116 \\
& 20140101140007 & 13 & $17: 00: 00$ & $17: 25: 00$ & 181301 \\
& 20140101140007 & 1 & $17: 25: 00$ & $17: 55: 00$ & 120303 \\
& 20140101140007 & -1 & $17: 55: 00$ & $6: 00: 00$ & 10101 \\
\hline
\end{tabular}

In order to compare travel information embedded in ATUS with the oft-used National Household Travel Survey (NHTS), we compute the histograms of total travel time per person for both surveys. We find that the histograms look similar. According to ATUS, the average travel time is $72 \mathrm{~min}$ and standard deviation $79 \mathrm{~min}$, while according to NHTS, they were 87 and $83 \mathrm{~min}$, respectively. Given the similarity we conclude it is acceptable to use ATUS to describe travel time.

\section{Methodology}

The analysis follows the following logical flow:

1. Identify group of individuals who benefit "most" from autonomous vehicles and otherwise similar contrasting segment;

2. Calculate activity patterns i.e., the average daily time spent on different activities for both groups;

3. Analyze statistical significance (confidence intervals and hypothesis testing).

4. Compare activity patterns of both groups to infer how the adopting group might shift activities given access to an AV.

Details of each step are described below.

While we emphasize the time budget perspective of AV adoption, costs associated with purchasing and maintenance cost are certainly important. Although vehicles with autonomous capabilities are currently expensive, $>\$ 50,000$, it is expected that their price will come down drastically in the near future. The TESLA model 3, for example, has autonomous capabilities and is priced at $\$ 35,000$. It has received around 455,000 pre-orders [32]. The average price of vehicles sold in 2015 was approximately $\$ 32,500$ [33]. While this is suggestive of lower incremental cost of AV functional, the future price of a fully-autonomous functionality is not yet clear. We address the question of affordability by examining per capita income of potential adopters.

\subsection{Identifying Groups that Benefit Most from AV}

The premise of the study is to identify groups of individuals who would benefit "most" from autonomous vehicles and compare the activity patterns of these potential adopters with contrasting segments. The contrasting segment is chosen as a group which, except for vehicle use, is otherwise similar in terms of profession for workers or age for retired individuals, to the potential AV adopters.

The following two drivers of AV adoption are considered here:

- People who spend long times in vehicles, particular driving a personal automobile, are losing out on other activities and hence might want automated vehicles to utilize that time. Our approach is to compare the activity pattern of people spending more time in vehicles with an otherwise 
similar cohort. Activities sacrificed for vehicle time presumably have high demand to be moved inside an AV.

- Older people often have trouble operating vehicles [34]. Autonomous vehicles can cater to the unfulfilled travel/activity demand of the elderly [11]. Our approach to address this group is to compare the driving time and activity pattern of older people who may have difficulty driving, with an otherwise similar cohort. The differences in travel time and activities between these two groups is indicative of change expected with adoption of AVs.

Based on these characteristics and with the help of ATUS, three potential groups that may adopt automated vehicles were identified. The first group of potential AV adopters is identified as full-time workers who spend substantially more time driving compared to other workers, hereafter termed "long commute drivers". We identify a subgroup of driving full-time workers with the top $20 \%$ for total travel time as the long commute drivers group. The contrasting counterpart is driving full-time workers with total travel time in the lower $80 \%$. As a time budget of $24 \mathrm{~h}$ per day is the same for everyone, long commute drivers must "sacrifice" activities to drive more than their counterparts. The choice of $20 \%$ top travel time as the $\mathrm{AV}$ adopters is not unique (e.g., versus $10 \%$ or $30 \%$ ), using $20 \%$ reveals more heterogeneity in activity patterns and leads to sizeable populations in both subgroups (see Table 2). Given our objective to compare groups that differ in travel behavior but not other attributes, we also distinguish worker groups by job type. ATUS classifies types of work into 6 categories. Management, professional and related activities were clubbed as "professional". Service, sales and office, farming, fishing, and forestry, construction and maintenance, and production transport and material moving were clubbed as "non-professional". The time use patterns of professionals were found to be reasonably different from other types of work (e.g., more time spent sleeping and less time in the main job), other work categories were more similar and aggregated into a "non-professional" category. Analysis of time use patterns is done separately for professional and non-professional work types.

The second group of potential AV adopters is identified as full-time workers who commute by rail or bus with substantially higher total travel times compared to other rail/bus commuters. The assumption is that these "long transit commuters" sacrifice more of their day to travel compared to other workers and thus are more motivated to switch to an AV. The choice of commuting by public transit versus an $\mathrm{AV}$ is complicated and unknown, depending on relative travel time, expense, and utility of time spent in AVs versus train/bus. We do not attempt to resolve the question of mode choice here, restricting the question to how activity patterns are different between long transit commuters and their contrasting counterpart. If the activities sacrificed for commuting can be done inside an $\mathrm{AV}$, this increases the chance that this group would commute by AV given the opportunity. As with the previous group, we break transit commuters into the potential AV adopters (top 20\% of total travel time) and the contrasting counterpart (bottom $80 \%$ of total travel time). Only individuals with a full work day of seven hours or more were analyzed.

The third group of potential AV adopters is chosen to be elderly for whom age poses a barrier to driving. There is no survey question in ATUS that measures ability to drive. Thus, we will use a rough proxy: We divide the retired population into $>75$ years old and $60-75$ years old subgroups and call the $>75$ group as $\mathrm{AV}$ adopters and the $60-75$ age range the contrasting counterpart. The choice of 75 years is not unique, there is no single age at which problems driving suddenly become prevalent. 75 years is chosen as the cutoff because 1) it reveals significant differences between older and younger groups while keeping both groups of sufficient size for statistical significance, and 2) the age of 75 is an often used boundary to distinguish the elderly population, e.g., [11]. While the specific numerical results depend on the age cutoff, qualitative trends are not affected.

Table 2 summarizes the population and sample sizes for the potential AV adopters and contrasting segments. 
Table 2. Groups identified as potential adopters of autonomous vehicles and their contrasting populations (ATUS = American Time Use Survey).

\begin{tabular}{|c|c|c|c|c|c|c|}
\hline Group Name & Sub-Group & $\begin{array}{l}\text { U.S. Pop. } \\
\text { (Million) }\end{array}$ & $\begin{array}{c}\text { ATUS } \\
\text { Sample Size }\end{array}$ & $\begin{array}{l}\text { Contrasting } \\
\text { Segment }\end{array}$ & $\begin{array}{l}\text { U.S. Pop. } \\
\text { (Million) }\end{array}$ & $\begin{array}{c}\text { ATUS } \\
\text { Sample Size }\end{array}$ \\
\hline $\begin{array}{l}\text { Long commute } \\
\text { drivers-professional }\end{array}$ & $\begin{array}{c}\text { Professional workers, } \\
\text { top } 20 \% \text { total } \\
\text { travel time }\end{array}$ & 8.8 million & 2849 & $\begin{array}{c}\text { Professional } \\
\text { workers, bottom } \\
80 \% \text { total travel time }\end{array}$ & 31.1 million & 11,539 \\
\hline $\begin{array}{l}\text { Long commute } \\
\text { drivers-non } \\
\text { professional }\end{array}$ & $\begin{array}{l}\text { Non-professional } \\
\text { workers, top } 20 \% \\
\text { total travel time }\end{array}$ & 10.2 million & 4089 & $\begin{array}{l}\text { Non-professional } \\
\text { workers, bottom } \\
80 \% \text { total travel time }\end{array}$ & 46.7 million & 16,615 \\
\hline $\begin{array}{l}\text { Long transit } \\
\text { commuters }\end{array}$ & $\begin{array}{l}\text { All workers taking } \\
\text { public transport, top } \\
20 \% \text { total travel time }\end{array}$ & 0.96 million & 150 & $\begin{array}{l}\text { All workers taking } \\
\text { public transport, } \\
\text { bottom } 80 \% \text { total } \\
\text { travel time }\end{array}$ & 3.84 million & 563 \\
\hline Elderly & Retired $>75$ years old & 15.9 million & 12,243 & $\begin{array}{c}\text { Retired }>60 \text { and } \\
\leq 75 \text { years old }\end{array}$ & 38.9 million & 21,075 \\
\hline
\end{tabular}

\subsection{Calculate Activity Patterns}

Activity patterns for each group are calculated in terms of total time spent (min/day), number of instances (\# of times done/day) and time per instance ( $\mathrm{min} /$ instance) for all 466 activities distinguished in ATUS. The 466 activities are referred as 3rd tier categories. These activities are aggregated into 108 2nd tier categories. These are further aggregated into 18 major activity categories. Activities are aggregated in the following way: i.e., relaxing and thinking, tobacco and drug use; television and movies (not religious), television and movies (religious), along with nine other such 3rd tier activities have been aggregated to 2nd tier category "relaxing and leisure." Second tier categories socializing and communicating; attending or hosting social events, relaxing and leisure, arts and entertainment (other than sports), and waiting associated with socializing, relaxing, and leisure are aggregated into major activity category "socializing, relaxing, and leisure".

In this analysis we use 3rd tier categories with a few exceptions. Television and movies (not religious) and television and movies (religious) have been aggregated into watching TV. "Travel time" have been obtained from major category "Traveling." Traveling time corresponds to time spent in personal vehicles as driver or passenger in taxis/limousines, buses and subways/trains. The 2nd tier activities, "attending or hosting social events" and "attending arts and entertainment" were aggregated into an activity we term "socializing".

Thirteen years of data are used (2003-2015) in order to increase the sample size for statistical significance (see Section 3.3). There is a potential concern that activity changes over the thirteen years might skew results. To test for this, we aggregate over different numbers of years and found little difference in average activity times. We thus use the 13-year period for improved statistics.

Note that we calculate national averages of activity patterns. geographic variations are expected, driven by factors such as differences in demographics and the built environment. Also, the results are contingent on the accuracy of the ATUS.

\subsection{Analysis of Statistical Significance}

The statistical significance of differences in averages between the groups were tested using confidence intervals and hypothesis testing, both assuming a t-distribution. For confidence intervals, we use $95 \%$ confidence and consider significant when the intervals do not exceed the difference in the average time of the two groups. In hypothesis testing, we assume a null hypothesis of the difference in the average time between the two groups as equal to zero and compare the $t$-value to significance of $5 \%$ [35]. Thirteen years of data were aggregated to ensure samples sizes yielding statistically significant results. 


\subsection{Compare Groups to Infer AV Demand/Use}

Differences in activities of adopters versus their segment are interpreted as indicators of how the adopters might shift their activities when using an AV. For example, if an AV adopter spends less time watching television compared to their counterpart, the idea is that the AV adopter will want to increase this time by adding in-vehicle television use. We select activities with statistically significant differences between the two groups for display and interpretation. For workers, the interpretation focuses on moving of activities into an AV. For the retired, the interpretation focuses on activities that may increase given improved access to mobility. Time spent in activities like grooming or food preparation have not been displayed or analyzed as they can neither be moved into an AV and nor do they require travel. The time spent in the displayed activities add up to $80 \%$ or more of the day and may be referred to as the main activities of relevant to the analysis.

\section{Results}

\subsection{Long Commute Drivers}

Figure 1 shows select results for average total time per day for professional full-time workers in the long commute group (upper $20 \%$ of total travel time) and the contrasting segment (lower $80 \%$ of total travel time). We show in Figure 1 the main activities with significant differences between the two groups.

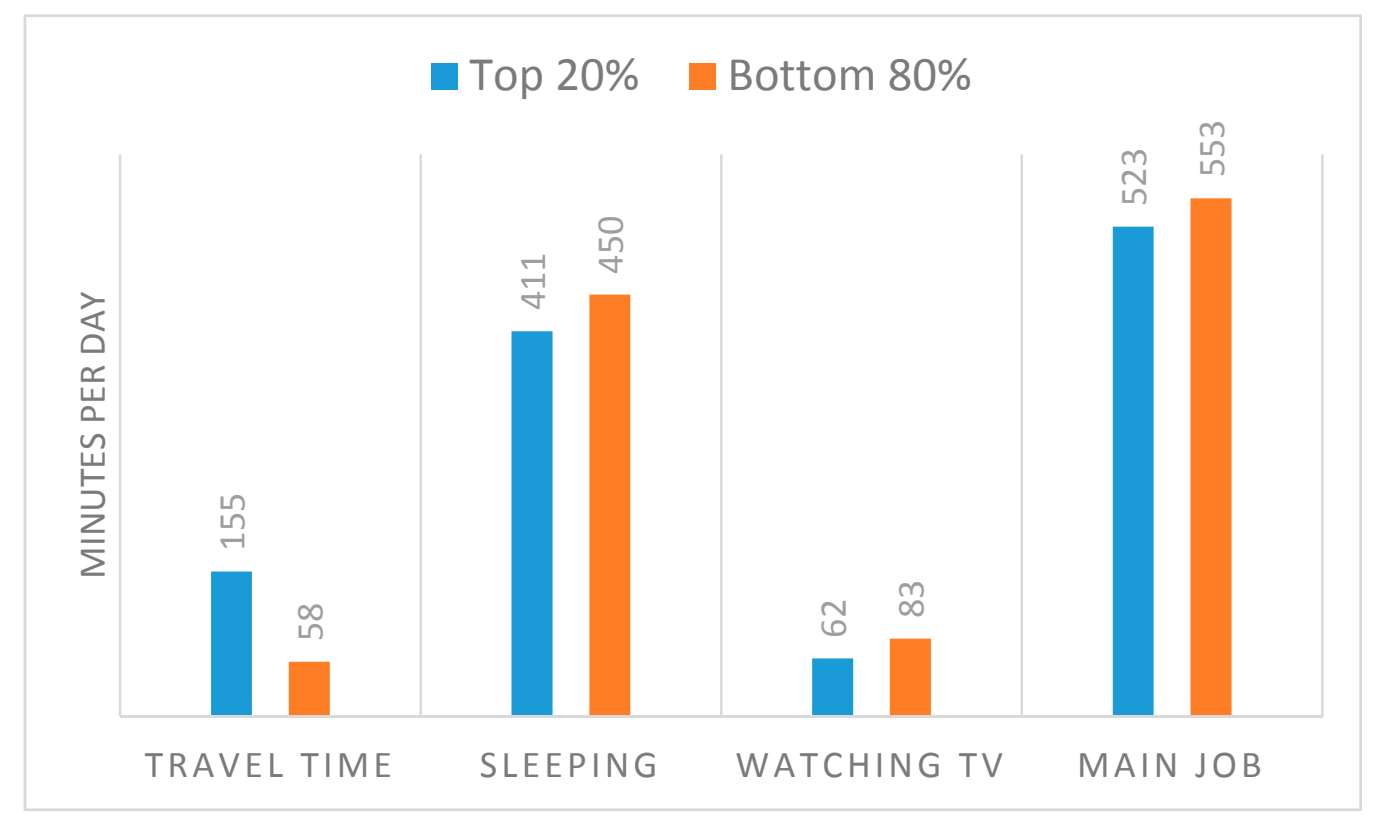

Figure 1. Professional workers: Average total time in a workday spent on select activities-top 20\% travel time (Long commute drivers) versus bottom $80 \%$ travel time segments.

The first result of note is that the heavy auto group travels a surprising $155 \mathrm{~min}$ or $2.6 \mathrm{~h}$ a day. In contrast, the bottom $80 \%$ group travels only $58 \mathrm{~min}$ per day, revealing significant heterogeneity in time use. The difference in travel time between the two groups is $97 \pm 1.3 \mathrm{~min}$ per day. The long commute group must be "sacrificing" other activities to create additional time to travel. Three activities dominate the difference in activity patterns: working, watching TV and movies and sleeping. The long commute professionals spent $30 \pm 4.3 \mathrm{~min}$ less on their main job, watched $21 \pm 3.3 \mathrm{~min}$ less TV, and slept for $39 \pm 3.7 \mathrm{~min}$ less compared to the bottom $80 \%$ counterpart. There are $7 \mathrm{~min}$ of additional difference in activity patterns spread over a variety of activities. These differences in activity times suggests that heavy travelers would, if using an $\mathrm{AV}$, spend travelling time mainly on a combination of 
sleep, work and video watching. We emphasize however that time differences are only suggestive of latent demand. The AV environment is not identical to home or the workplace, actual use of time inside an AV is ultimately an empirical question answerable after the technology has diffused and drivers have had time to become accustomed to it.

The results were similar for non-professional workers. The top $20 \%$ spent about $48 \pm 3.7,33 \pm 3.3$ and $23 \pm 3.6 \mathrm{~min}$ less time on sleeping, watching TV and main job respectively. They spent $96 \pm 1.1 \mathrm{~min}$ more traveling.

It is important to note that while different individuals might have the same total travel time, their travel profiles may be very different. Figure 2 shows example activity patterns for 4 individuals in a space-time "prism" as dubbed by Hägerstrand [29]. Individuals A \& B have travel time equal to the average of the top $20 \%, C \& D$ have travel time equal to the average of bottom $80 \%$. As seen in Figure 2, the activity patterns of all four are very different. Individual A only commutes to work and drives for lunch. Individual B on the other hand drives to some else's house on the way to and back from work to pick up and drop off the kids. $C$ has a regular shift and drives to the mall on the way back from home. D has late day and drives only to and back from work. Figure 2 is just meant to illustrate how activity, location and transport play out during a day, we do not quantitatively analyze heterogeneity using such figures.

Top 20\%, professionals

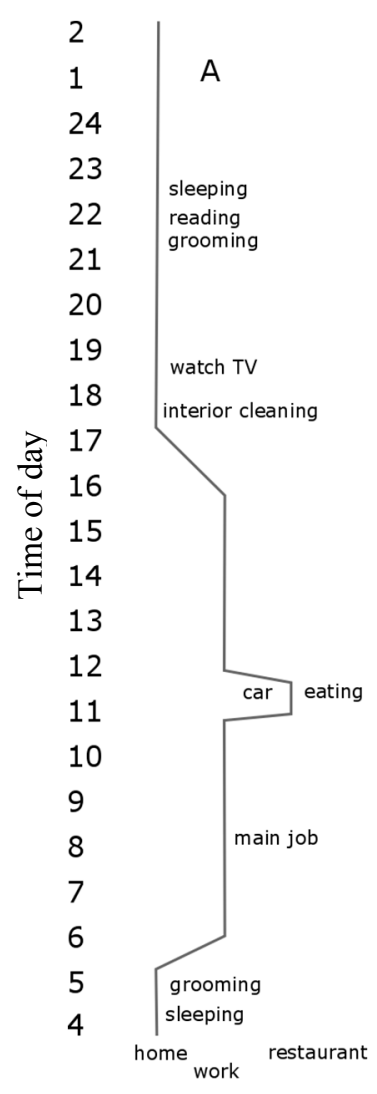

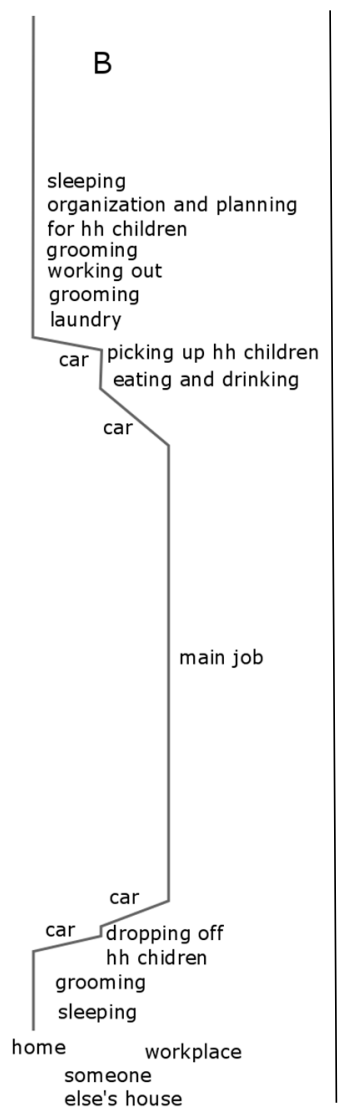

Bottom $80 \%$, professionals

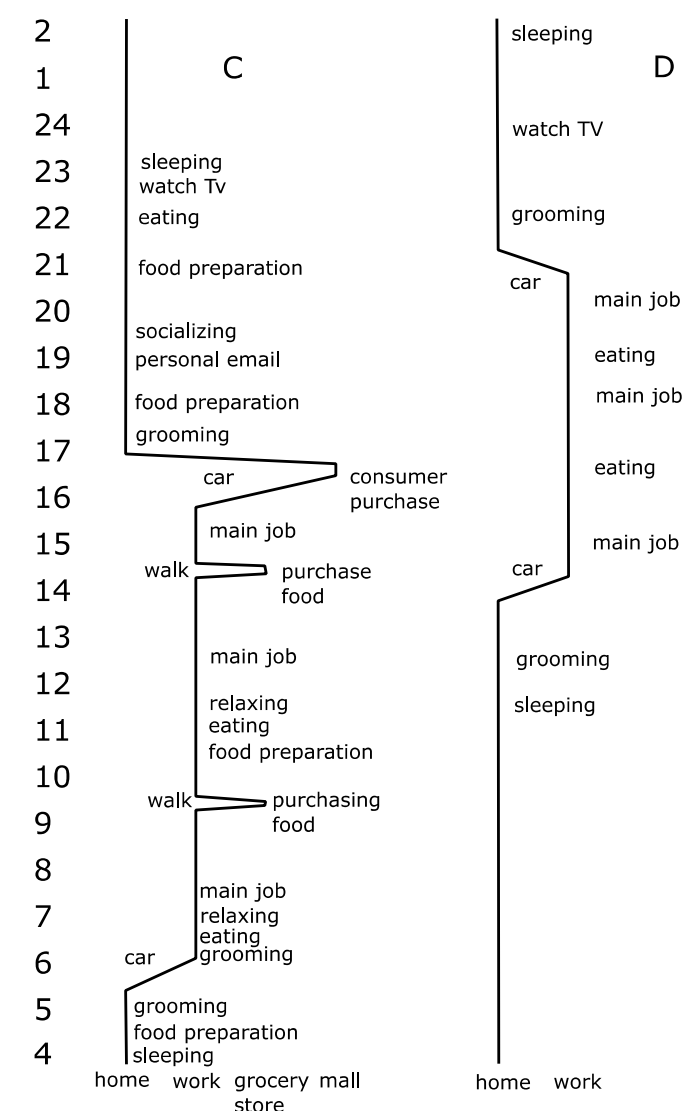

Figure 2. Activity patterns of two sample professional individuals (A\&B) with travel time equal to the average of the top $20 \%$ and two (C\&D) with travel time equal to the average of the bottom $80 \%$. The $Y$-axis represents time of day, starting from early morning at the bottom and time running upward by hour. The vertical length of a line is the duration of an activity. A discrete $X$ axis represents location of an activity ( $\mathrm{hh}=$ household), the left-hand vertical line is home, vertical lines to the right of this are workplace, restaurant, or other location. Slanted lines refer to travel between locations. 
Although AVs may be expected to be more expensive than conventional vehicles, it is unlikely that they will be priced beyond the reach of ordinary consumers. For example, as mentioned earlier, the Tesla Model 3, which has autonomous capabilities, has a starting price that is essentially equal to the price the average personal vehicle sold in the US today. In our analysis, we noticed that professionals have significantly higher salaries, earning $67 \%$ and $74 \%$ more than non-professionals for top $20 \%$ of the travelers and bottom $80 \%$ travelers respectively. This indicates that, given the purchasing power of this group and the probable prices of AVs, this group is likely to be able to afford AV when they become available. Moreover, one should note that while many professionals are not paid by the hour, higher income workers in some sense have a higher opportunity cost of not working. This group is presumably more interested in being able to work inside an AV.

The large differences in time spent working, sleeping and watching TV and movies between heavy commuters and the lower $80 \%$ counterparts suggests a latent demand for those activities. AV designs that enable these activities to be done in the vehicle are likely to be particularly attractive to the long commute drivers.

\subsection{Long Transit Commuteres}

In this analysis, workers that have at least one trip on public transport were selected, this group represents $4.7 \%$ of the US working population. As with the previous analysis, the total travel time for calculated and the public transport riders divided into Top $20 \%$ and Bottom $20 \%$ cohorts. The total time spent for activities with significant differences between the two groups is shown in Figure 3.

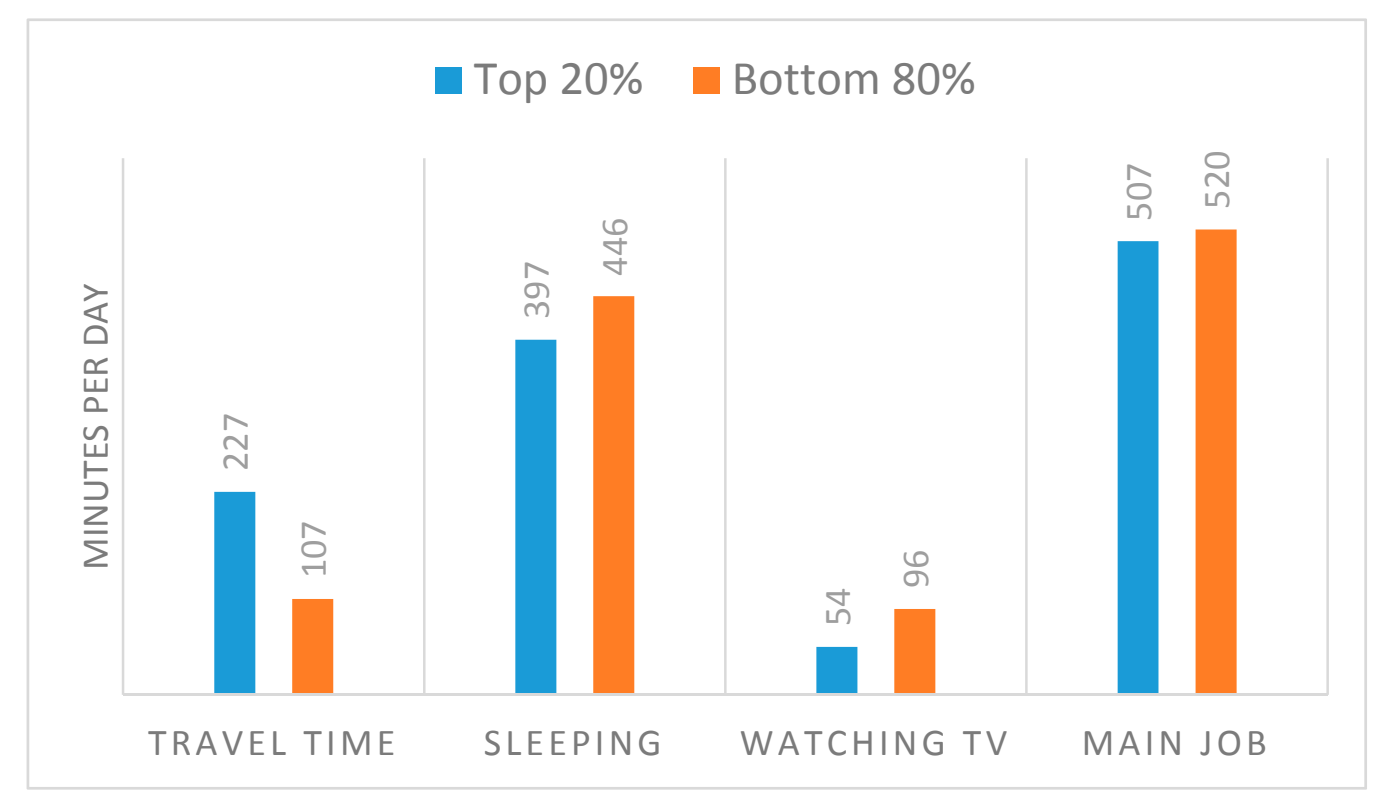

Figure 3. Workers riding public transit: Average total time spent in a workday on select activities-top $20 \%$ travel time (Long transit commuters) against bottom $80 \%$ travel time counterpart.

The top $20 \%$ of travelers spend $120 \pm 12$ more min traveling than the bottom $80 \%$ group. To make up for this additional travel time, they spend $49 \pm 19$ min less sleeping and $42 \pm 17$ min less watching TV. They also spend 13 min less time on their main job, though this difference is not significant with a $95 \%$ confidence interval. Note that the confidence intervals are much larger for the public transport analysis because the sample sizes are much smaller than for the auto travelers. While the numbers differ, qualitatively the trends are the same for both public transport riders and auto drivers: additional travel time is made by sacrificing sleep, TV watching, and work.

Figure 4 shows sample activity patterns for public transport riders. Individuals $\mathrm{E}$ and $\mathrm{F}$ travel a time equal to the average of the top $20 \%$. Individuals $\mathrm{G}$ and $\mathrm{H}$ have travel time equal to the average of 
the bottom $80 \%$. While $\mathrm{E}$ has very long commute to work, F travels to work by car but then uses public transport for leisure activities, in this case going to a show. Individuals $\mathrm{G}$ and $\mathrm{H}$ use public transport for commuting.

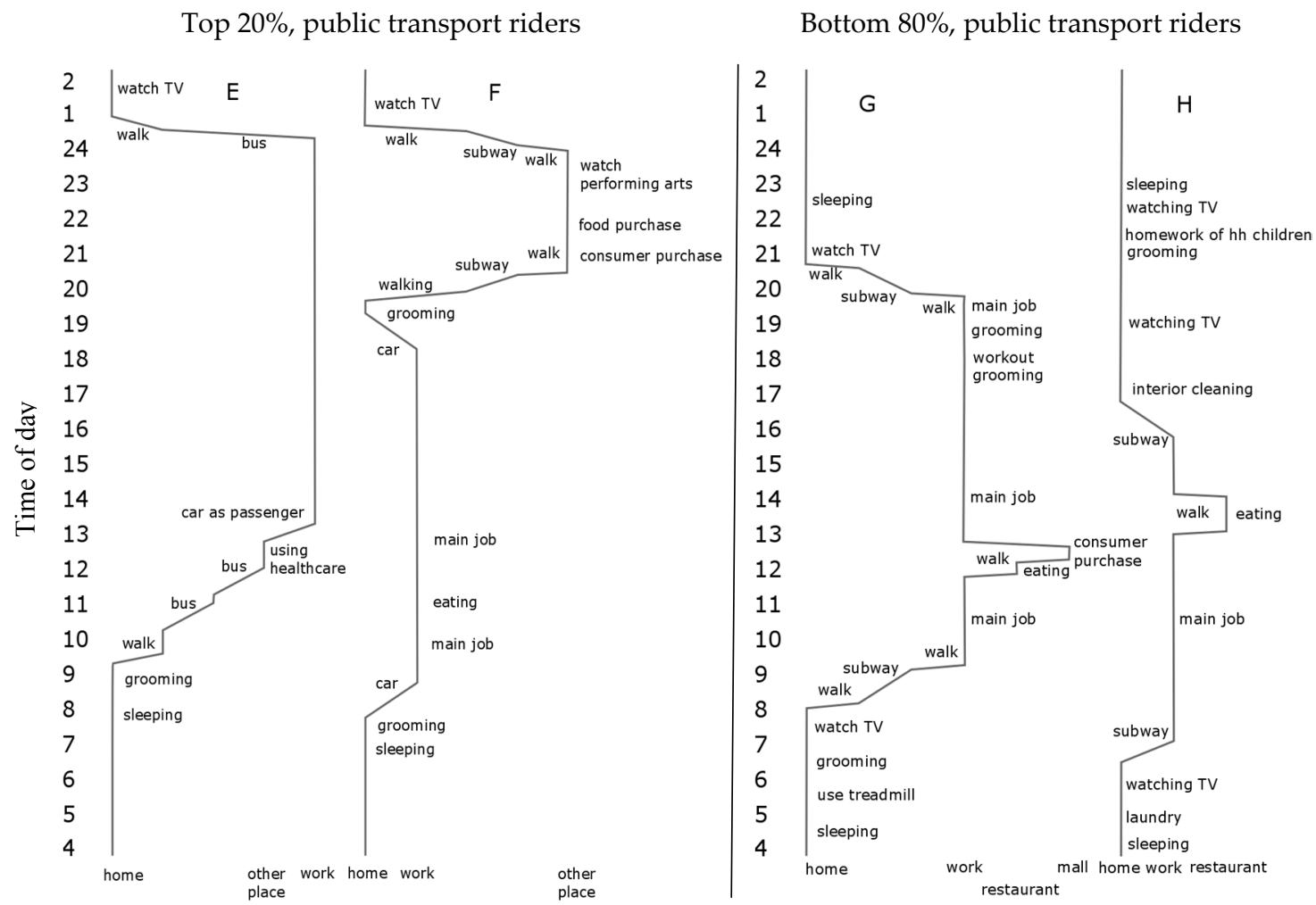

Figure 4. Activity patterns of two sample working individuals riding public transport with travel time equal to average of top $20 \%$ ( $\mathrm{E}$ and $\mathrm{F}$ ) and bottom $80 \%$ ( $\mathrm{G}$ and $\mathrm{H}$ ). The $Y$-axis represents time of day, starting from early morning at the bottom and time running upward by hour. The vertical length of a line is the duration of an activity. A discrete $X$ axis represents location of an activity (hh = household), the left-hand vertical line is home, vertical lines to the right of this are workplace, restaurant, or other location. Slanted lines refer to travel between locations.

There is potential for autonomous vehicles to shift these long commuters from public toward private transport. First, this group is relatively wealthy and thus more able to afford AV. Of all groups analyzed in this study, top 20\% travel time public transport riders have the highest income, averaging $\$ 1027$ per week. Second, while ATUS does not include questions addressing why respondents take public transport, we posit that this group consists mainly of city residents commuting by public transport to avoid driving in city traffic. Studies indicate that there is a strong relationship between income and mode choice [36,37] with increasing income people tend towards private transport. These long commuters are wealthy enough to afford private vehicles, their use of public transport presumably reflects an aversion to driving in city traffic, a need to save time, or both $[37,38]$. An AV would increase the utility of time spent in congested traffic and make parking easier, thus potentially attracting riders away from public transit.

Our argument is premised on the idea that AV functionality would attract workers from public transport to a household automobile. There is potential for the opposite: autonomous vehicles will also enable new forms of shared public and private transportation. Multi-passenger use of AV (e.g., Uber Pool) could realize some of the higher vehicle occupancy benefits of buses and trains while delivering more flexibility. AVs could also evolve into low-cost single passenger driverless taxis. Driverless taxis are now operating in several cities around the world including Pittsburgh, Boston, 
Singapore, and Tokyo [39]. Currently, there are many startups that are working on the idea of using autonomous vehicles as taxi services (Ford, Uber, GM, Nutonomy, and Alphabet). It is not clear how the private AV use versus shared model question will play out. A study by the American Public Transportation Association found that $\mathrm{AV}$ s provide greater access to shared modes such as bike-sharing, car-sharing, and ride-sourcing and so the use of public transit may increase [40]. On the other hand, AVs also significantly enhance the utility of private vehicles so it can be argued that increased use of AVs will suppress the demand for public transport. The question of private versus shared AVs is of great importance, and the answer depends on multiple factors, including future prices of AVs and fuel. We do not address the private/shared AV question here; rather, we comment on the implications of public transport riders switching to private AVs.

\subsection{Elderly and Retired Individuals}

The other group considered in this study is elderly retired individuals to characterize a latent demand for out of home activities, which autonomous vehicles would presumably help cater to. Age severely impairs the ability to drive and consequently makes the elderly dependent on other for their mobility, thus reducing their out of home activities and their ability to socialize [34,41-43]. While it has been suggested that public transport should be developed to cater to such groups [44], in practice, many elderly individuals in the US live in remote areas where such development is unlikely. The group of retired individuals were divided into two age groups, those of ages between 60 and 75 years and those over 75 years. The groups were examined for relevant activities with significant time differences. The results are shown in Figure 5. Note that the US population of retired individuals above 75 years of age is approximately 16 million.

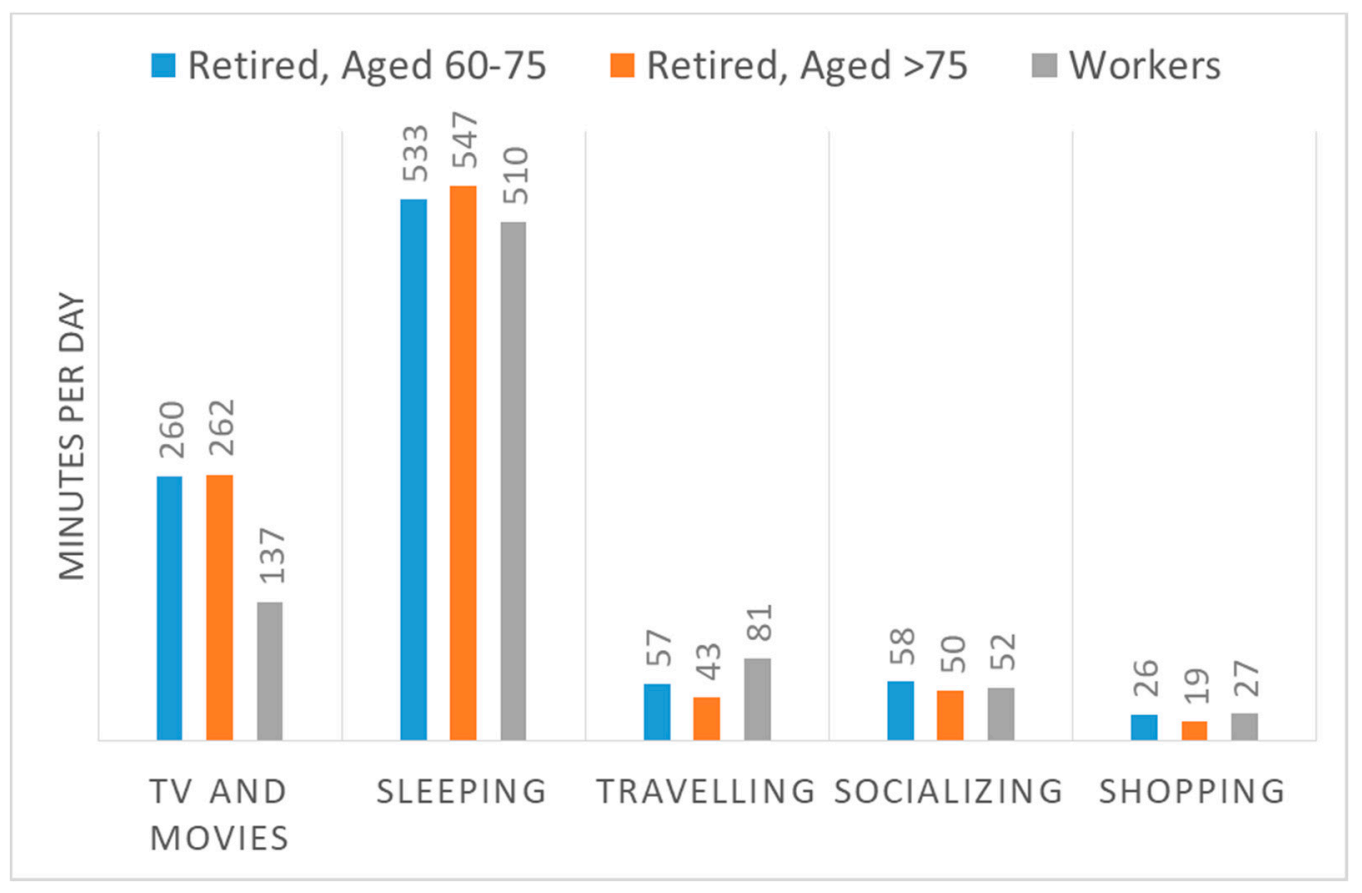

Figure 5. Retired persons: Average total time spent per day on select activities—retirees $>75$ years old versus 60-75 years old. Time spent by workers (all ages) is displayed to show differences between working and retired time use patterns.

In summary, elderly retirees spend less time traveling, shopping and socializing than their younger counterparts. Retired people aged $>75$ years spend on an average $14 \pm 1.6 \mathrm{~min}$ less time traveling and $7 \pm 1 \mathrm{~min}$ less time shopping and $8 \pm 2.1 \mathrm{~min}$ less socializing than retired people in the age bracket 60-75. They spend as much time watching TV and more time sleeping (14 $\pm 2.8 \mathrm{~min}$ ). 
Younger retirees on average spend 50 more min outside of the home than older retirees. In our analysis, we were able to account for $29 \mathrm{~min}: 14 \mathrm{~min}$ traveling, $7 \mathrm{~min}$ shopping, and $8 \mathrm{~min}$ socializing. The remaining $21 \mathrm{~min}$ is distributed among several activities such as visits related to religious practices and visits to medical centers.

These results suggest there might be demand from more elderly people to use AVs to do more shopping and socializing. However, we need to note that access to transportation is just one of many factors leading to changes in lifestyle patterns with increasing age. Disentangling mobility and age-related effects on activity patterns is beyond the scope of this work.

Retired individuals spend more time sleeping and watching TV and less time traveling than working individuals. The heterogeneity of TV watching patterns according to age and other demographic variables was analyzed in Sekar et al., 2016 [17].

As with the previous groups, there is significant heterogeneity in the activity patterns of the retired individuals. Figure 6 shows sample activity of two retired individuals aged between 60 and 75 (I\&J) and two aged over $75(\mathrm{~K} \& \mathrm{~L})$. All individuals have a travel time equal to the average of their group.

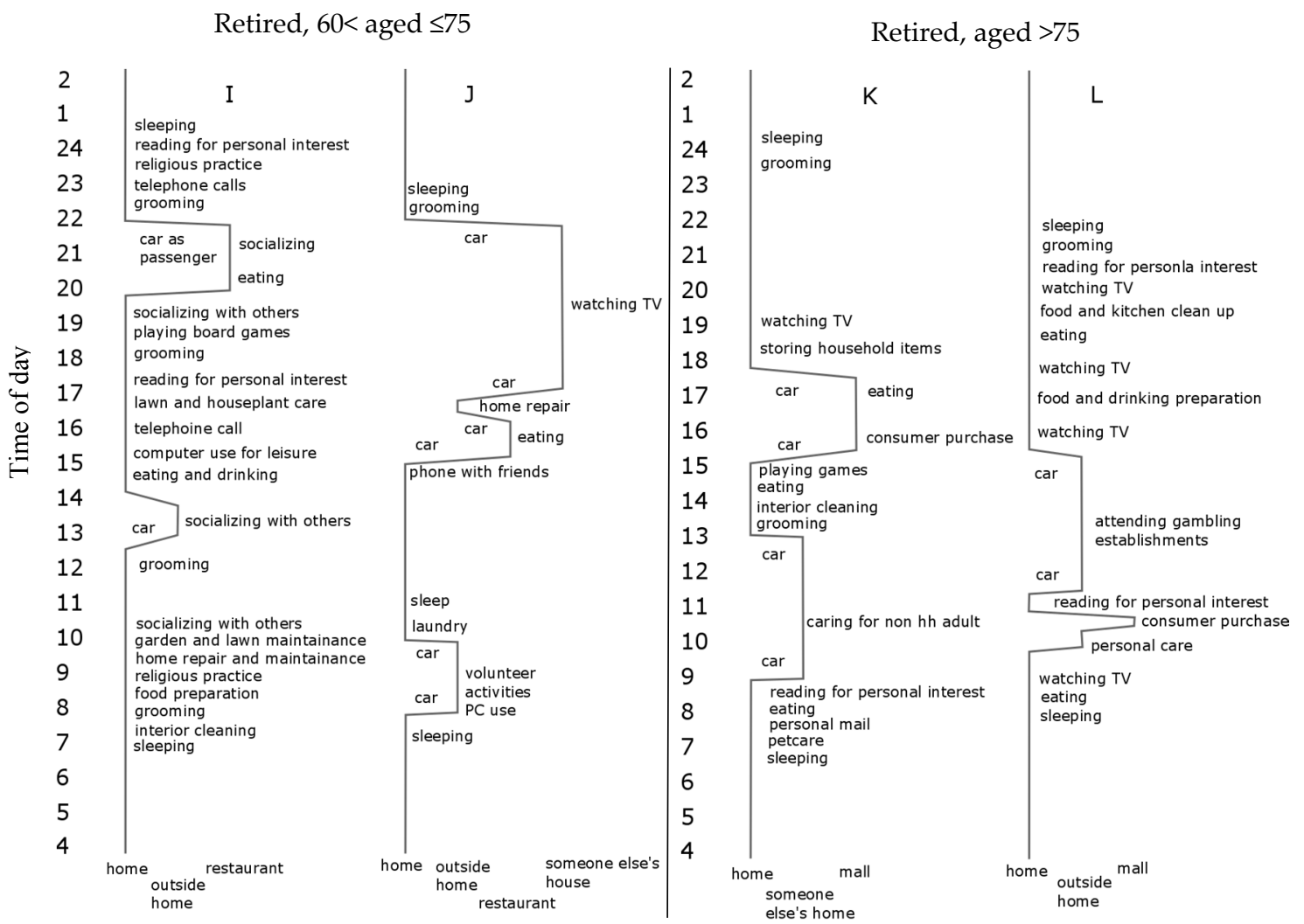

Figure 6. Activity pattern of two sample retired individuals with travel time equal to the average for age 60-75 (I\&J) and age $>75$ (K\&L). The $Y$ axis represents time of day. The $Y$-axis represents time of day, starting from early morning at the bottom and time running upward by hour. The vertical length of a line is the duration of an activity. A discrete $X$ axis represents location of an activity (hh = household), the left-hand vertical line is home, vertical lines to the right of this are workplace, restaurant, or other location. Slanted lines refer to travel between locations.

Contrasting results for adoption of AVs by the elderly with Harper et al., 2016, rather than using vehicle miles traveled, we use time use data to assess activities the elderly and retired are allocating their time. Harper, et al., 2016 assume that retired population would use AVs to result in similar travel behavior to the working population. Our analysis indicates differences in retired and elderly 
populations, suggesting that those aged $>75$ year could benefit even more than those aged between 60 and 75, as mobility and out-of-home activity is reduced substantially with age.

\section{Conclusions}

For AV design, these results suggest that the features most in demand by workers with long commutes are:

- Internet connectivity;

- Designs enabling comfortable use of computers;

- Displays enabling media watching;

- Seats suitable for sleeping.

These features would enable drivers to catch up on the media watching, work, and sleep they are sacrificing for long travel times. Heavy travelers have higher salaries to afford the higher price tag of AVs.

In the adoption of $\mathrm{AV}$, the extent to which wealthier riders of public transport might switch to an AV commute is important from economic, social, and environmental perspectives. $\mathrm{AV}$ functionality replaces the aggravation of navigating congested traffic with a choice among various useful/entertaining activities. Self-parking can address time lost in urban parking. There is a large population of commuters whose switch from public to private transport may significantly increase the number of vehicles on the road, which could undermine the viability of some public transport options. These are important topics to address in future research. In this work, we showed that there is a substantial and well-paid population sacrificing important activities to travel very long times on public transport.

Elderly retired individuals could also benefit from AVs. A study by van den Berg et al., (2016) mentioned loneliness as an important aspect of quality of life. He argued that transportation options reduce loneliness and improves the quality of life of the elderly [43]. While it is difficult to quantitatively predict how retirees would change their lifestyle given access to AVs, we found that a large elderly population driving less and consequently reducing time spent in out-of-home activities like shopping and socializing.

To summarize our view of the role of this work in the future assessment of $\mathrm{AV}$, we first note that the time-use perspective used here makes it very clear that the impacts of $\mathrm{AV}$ go beyond the transport sector. Enabling travel-restricted populations, e.g., the elderly retired, also affects their destinations, e.g., retail shops or entertainment facilities. Second, we also note that the dramatic differences in activity patterns of heavy and other travelers suggest the potential for significant re-organization of lifestyles given access to AV. Finally, while we do not pursue the idea further here, time-use activity patterns are a natural quantitative language through which to express and model AV-induced lifestyle shifts and ensuing implications for transport infrastructure and policy [45-47].

Acknowledgments: This research was supported by the Ford Motor Company.

Author Contributions: Eric Williams and Roger Chen supervised the overall research, all authors made contributions to the content. Saptarshi Das and Ashok Sekar manipulated data and performed the analyses. The article was mainly written by Saptarshi Das and Ashok Sekar, with contributions from Eric Williams, Roger Chen, Hyung Chul Kim, and Timothy J. Wallington.

Conflicts of Interest: The authors declare no conflict of interest.

\section{References}

1. Manyika, J.; Chui, M.; Bughin, J.; Dobbs, R.; Bisson, P.; Marrs, A. Disruptive Technologies: Advances That Will Transform Life, Business, and the Global Economy; McKinsey Global Institute: San Fransisco, CA, USA, 2013.

2. Anderson, J.M.; Kalra, N.; Stanley, K.D.; Sorensen, P.; Samaras, C.; Oluwatola, O.A. Autonomous Vehicles: A Guide for Policy Makers; RAND Corporation: Santa Monica, CA, USA, 2014. 
3. Fagnant, D.J.; Kockelman, K.M.; Bansal, P. Operations of a shared autonomous vehicle fleet for the Austin Texas market. Transp. Res. 2015, 2536, 98-106. [CrossRef]

4. Greenblatt, J.B.; Saxena, S. Autonomous taxis could greatly reduce greenhouse-gas emissions of US light-duty vehicles. Nat. Clim. Chang. 2015, 5, 860-863. [CrossRef]

5. Chester, M.V.; Horvath, A.; Madanat, S. Comparison of life-cycle energy and emissions footprints of passenger transportation in metropolitan regions. Atmos. Environ. 2010, 44, 1071-1079. [CrossRef]

6. Vine, S.L.; Zolfaghari, A.; Polak, J. Autonomous cars: The tension between occupant experience and intersection capacity. Transp. Res. Part C 2015, 52, 1-14. [CrossRef]

7. Qu, Z.; Wang, J.; Hull, R.A. Cooperative control of dynamical systems with application to autonomous vehicles. Inst. Electr. Electron. Eng. 2008, 53, 894-911. [CrossRef]

8. Aguiar, A.P.; Hespanha, J.P. Trajectory-tracking and path-following of underactuated autonomous vehicles with parametric modeling uncertainty. Inst. Electr. Electron. Eng. 2007, 52, 1362-1379. [CrossRef]

9. Likhachev, M.; Ferguson, D. Planning Long Dynamically feasible maneuvers for autonomus vehicles. Int. J. Robot. Res. 2009, 28, 933-945. [CrossRef]

10. Feddema, J.T.; Lewis, C.; Schoenwald, D.A. Decentralized control of cooperative robotic vehicles: Theory and application. Inst. Electr. Electron. Eng. 2002, 18, 852-864. [CrossRef]

11. Harper, C.D.; Hentrickson, C.T.; Mangones, S.; Samaras, C. Estimating potential increases in travel with autonomous vehicles for the non-driving, elderly and people with travel-restrictive medical conditions. Transp. Res. Part C 2016, 72, 1-9. [CrossRef]

12. Gallaghera, K.S.; Muehlegger, E. Giving green to get green? Incentives and consumer adoption of hybrid vehicle technology. J. Environ. Econ. Manag. 2011, 61, 1-15. [CrossRef]

13. Helvestona, J.P.; Liu, Y.; Feitc, E.M.; Fuchsa, E.; Klampfl, E.; Michaleka, J.J. Will subsidies drive electric vehicle adoption? Measuring consumer preferences in the U.S. and China. Transp. Res. Part A Policy Pract. 2015, 73, 96-112. [CrossRef]

14. Yeh, S. An empirical analysis on the adoption of alternative fuel vehicles: The case of natural gas vehicles. Energy Policy 2007, 35, 5865-5875. [CrossRef]

15. Axhausen, K.W.; Garling, T. Activity-based approaches to travel analysis: Conceptual frameworks, models, and research problems. Transp. Rev. 1992, 12, 323-342. [CrossRef]

16. Kitamura, R.; Fujii, S.; Pas, E.I. Time-use data, analysis and modeling: Toward the next generation of transportation planning methodologies. Transp. Policy 1997, 4, 225-235. [CrossRef]

17. Sekar, A.; Chen, R.; Williams, E. Heterogeniety in time and energy use of watching television. Energy Policy 2016, 93, 50-58. [CrossRef]

18. Yap, M.D.; Correia, G.; Van Arem, B. Valuation of travel attributes for using automated vehicles as egress transport of multimodal train trips. Transp. Res. 2015, 10, 462-471. [CrossRef]

19. U.S. Department of Transportation (USDOT). The Impact of Automated Transit, Pedestrian, and Bicycling Facilities on Urban Travel Patterns; U.S. Department of Transportation (USDOT): McLean, VA, USA, 2013.

20. Haword, D.; Dai, D. Public Perceptions of Self-driving Cars: The Case of Berkeley, California. In Proceedings of the TRB 93rd Annual Meeting of the Transportation Research Board, Berkeley, CA, USA, 1 August 2013.

21. Wadud, Z.; MacKenzie, D.; Leiby, P. Help or hindrance? The travel, energy and carbon impacts of highly automated vehicles. Transp. Res. Part A Policy Pract. 2016, 86, 1-18. [CrossRef]

22. Gucwa, M. Mobility and energy impacts of automated cars. In Proceedings of the Automated Vehicles Symposium, San Francisco, CA, USA, 14-18 July 2014.

23. Childress, S.; Nichols, B.; Charlton, B.; Coe, S. Using an activity-based model to explore the potential impacts of automated vehicles. Transp. Res. Record J. Transp. Res. Board 2015, 2493, 99-106. [CrossRef]

24. Brown, A.; Gonder, J.; Repac, B. An analysis of possible energy impacts of automated vehicle. In Road Vehicle Automation; Springer: Cham, Switzerland, 2014; pp. 137-153.

25. Fagnant, D.J.; Kockelman, K. Preparing a nation for autonomous vehicles: Opportunities, barriers, and policy recommendations for capitalilzing on self-driven vehicles. Transp. Res. 2015, 77, 167-181.

26. Kitamura, R. A model of daily time allocation to discretionary out-of-home activities and trips. Transp. Res. Part B Methodol. 1984, 18, 255-266. [CrossRef]

27. Jones, P.M.; Dix, M.C.; Clarke, M.I.; Heggie, I.G. Understanding Travel Behavior; Gower: Aldershot, UK, 1983. 
28. Chen, R.B.; Armington, W. Household activities and travel patterns with autonomous vehicles: In-vehicle activity decisions. In Proceedings of the TRB 95th Annual Meeting, Washington, DC, USA, 10-14 January 2016.

29. Hägerstrand, T. What about People in Regional Science. Pap. Reg.Sci. Assoc. 1970, 24, 7-21. [CrossRef]

30. Templeton, B. Where Robot Cars (Robocars) Can Really Take Us. Available online: http:/ /www.templetons. $\mathrm{com} / \mathrm{brad} /$ robocars/robot-cars.html (accessed on 17 March 2016).

31. Bureau of Labor Statistics. American Time Use Survey; Bureau of Labor Statistics: Washington, DC, USA, 2015.

32. Bhuiyan, J. Tesla Saw about 63,000 Cancellations of Model 3 Pre-Orders. Available online: https:// www.cnbc.com/2017/08/03/tesla-saw-about-63000-cancellations-of-model-3-pre-orders.html (accessed on 10 October 2017).

33. Healey, J.R. Average New Car Price Zips 2.6\% to \$33,560. Available online: https:/ /www.usatoday.com/ story/money/cars/2015/05/04/new-car-transaction-price-3-kbb-kelley-blue-book/26690191/ (accessed on 24 October 2017).

34. Rosenbloom, S. Driving cessation among older people: When does it happen and what impact does it have? Transp. Res. Record J. Transp. Res. Board 2012, 1779, 93-99. [CrossRef]

35. Yale. Comparison of Two Means. Available online: http://www.stat.yale.edu/Courses/1997-98/101/ meancomp.htm (accessed on 21 June 2017).

36. Anable, J. 'Complacent Car Addicts' or 'Aspiring Environmentalists'? Identifying travel behaviour segments using attitude theory. Transp. Policy 2005, 12, 65-78. [CrossRef]

37. Paulley, N.; Balcombe, R.; Mackett, R.; Titheridge, H.; Preston, J.; Wardman, M.; Shires, J.; White, P. The demand for public transport: The effects of fares, quality of service, income and car ownership. Transp. Policy 2006, 13, 295-306. [CrossRef]

38. Beirão, G.; Cabral, J.A.S. Understanding attitudes towards public transport and private car: A qualitative study. Transp. Policy 2007, 14, 478-489.

39. Bettencourt, L. These Cities Could Lead the Driverless Car Revolution. Available online: http:/ / fortune. com/2016/10/04/driverless-cars-uber-lyft-google-baidu/ (accessed on 10 June 2017).

40. SUMC. Shared Mobility and the Transformation of Public Transit; Shared-Use Mobility Center (SUMC): Chicago, IL, USA, 2016.

41. Stutts, J.C. Do older drivers with visual and cognitive impairments drive less? J. Am. Geriatr. Soc. 1998, 46, 854-886. [CrossRef] [PubMed]

42. Marottoli, R.A.; Ostfeld, A.M.; Merrill, S.S.; Perlman, G.D.; Foley, D.J.; Cooney, L.M. Driving cessation and changes in mileage driven among elderly individuals. J. Gerontol. 1992, 48, 255-260. [CrossRef]

43. Van den Berg, P.; Astrid, K.; Boy de, K.; Aloys, B. Ageing and loneliness: The role of mobility and the built environment. Travel Behav. Soc. 2016, 5, 48-55. [CrossRef]

44. Rahman, M.M.; Strawderman, L.; Adams-Price, C.; Turner, J.J. Transportation alternative preferences of the aging population. Travel Behav. Soc. 2015, 4, 22-28. [CrossRef]

45. Davies, A. Google's Self-Driving Car Caused Its First Crash. Available online: https://www.wired.com/ 2016/02/googles-self-driving-car-may-caused-first-crash/ (accessed on 6 May 2017).

46. Google. Google Self-Driving Car Project Monthly Report; Google: Mountain View, CA, USA, 2015.

47. Hsu, T. CES 2013: Lexus Driverless Car: Technology Alone Is Not the Answer. Available online: http:/ / articles.latimes.com/2013/jan/07/autos/la-fi-tn-ces-hy-lexus-driverless-car-20130107 (accessed on 5 June 2017).

(C) 2017 by the authors. Licensee MDPI, Basel, Switzerland. This article is an open access article distributed under the terms and conditions of the Creative Commons Attribution (CC BY) license (http:/ / creativecommons.org/licenses/by/4.0/). 